\title{
Frontières
}

\section{ENCREVÉ-LAMBERT, Marie-Hélène, La Mort, Paris, Bayard, 2003 [1999], 142 p.}

\section{Louise Rousseau}

Volume 17, numéro 1, automne 2004

URI : https://id.erudit.org/iderudit/1073617ar

DOI : https://doi.org/10.7202/1073617ar

Aller au sommaire du numéro

\section{Éditeur(s)}

Université du Québec à Montréal

\section{ISSN}

1180-3479 (imprimé)

1916-0976 (numérique)

Découvrir la revue

\section{Citer ce compte rendu}

Rousseau, L. (2004). Compte rendu de [ENCREVÉ-LAMBERT, Marie-Hélène, La Mort, Paris, Bayard, 2003 [1999], 142 p.] Frontières, 17(1), 97-97.

https://doi.org/10.7202/1073617ar d'utilisation que vous pouvez consulter en ligne.

https://apropos.erudit.org/fr/usagers/politique-dutilisation/ 
ENCREVÉ-LAMBERT, Marie-Hélène La Mort

Paris, Bayard, 2003 [1999], 142 p.

LA VIE DE FAMILLE

DES REPPRES POUR BIEN VIVRE AVEC VOS ENFANTS

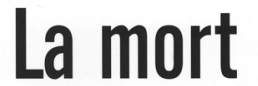

Marie-Hélène Encrevé-Lambert

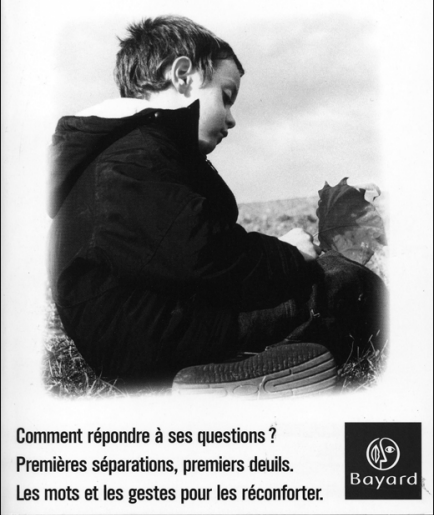

La mort, un thème délicat à aborder dans une collection pour les parents: que dire aux enfants sur la mort, comment en parler avec de tout petits enfants.

L'auteure, psychanalyste pour adultes et enfants, explore le sujet dans ce livre détaillé où alternent les réflexions et les vignettes cliniques.

Il faut parler de la mort avec les enfants, nous dit-elle, surtout dans ce monde contemporain où la mort "télévisuelle» est omniprésente dans les informations, au cinéma alors qu'elle fait si peu partie des choses de la vie: on naît et meurt à I'hôpital, on voit peu le corps sans vie.

L'auteure nous propose une réflexion sur les interrogations des enfants face à la mort. Elle situe le premier deuil, la première expérience de séparation au moment de la naissance. Reprenant les étapes du développement psychique (se référant entre autres à Mélanie Klein, citant Françoise Dolto), elle nous convainc que les enfants sont très tôt capables de comprendre si on leur parle de perte et de deuil.

Elle nous rappelle que les premières rencontres avec la mort - la fin de la vie - surviennent dans le quotidien du contact avec la nature, un animal qui ne bouge pas, une fourmi écrasée. Puis, peut-être y aura-t-il la mort, la peine liée à la perte d'un animal familier et un parent interpellé par les questions de l'enfant. Mais que dire lors du décès d'un proche, lors de la perte d'un être aimé, que dire face à la mort qui attriste les adultes, comment être présent à la préoccupation des enfants. L'auteure aborde avec doigté certains décès difficiles: comment parler avec un enfant de la mort d'un de ses parents, de la maladie mortelle dont l'enfant est atteint, de certaines morts plus difficiles: le suicide, les disparus, ceux dont on ne retrouve pas le corps.

Elle décrit certaines réactions possibles des enfants lors de décès de proches et insiste sur l'isolement lié au silence des parents: «Nombreux sont les témoignages d'enfants effondrés par l'impossibilité des parents de parler de la mort avec eux. De cette incapacité à dire simplement les choses, les parents souffrent, tout comme les enfants." (p. 46)

Le texte est parsemé d'exemples de toutes ces phrases floues que les adultes utilisent pour éviter de parler vraiment de mort. Elle insiste sur la parole: «Entre se taire et mal dire, il y a toujours une place pour un parler vrai et une présence qui reconnaît la souffrance de l'enfant et y prend part, en l'écoutant et en la partageant.» (p. 16)

Le thème de la mort et des enfants amène souvent les auteurs à discuter de la compréhension de la notion de mort, de son irréversibilité, en fonction de l'âge et de l'étape du développement cognitif, affectif. Dans ce livre, le sujet est approché autrement: pour l'auteure, les enfants, quel que soit leur âge, sont capables d'avoir une "certaine" compréhension de la mort, l'important étant de parler à l'enfant du décès, de la perte, de la douleur et ce dans l'esprit de maintenir le lien par la parole et d'éviter un silence qui isole.

La parole, parler des vraies choses, tel est le message qui a attiré mon attention à la première lecture de ce texte. La nécessité de parler avec l'enfant est un message important à transmettre aux parents, mais... car il y a un mais, parler peut être interprété de bien des façons et conduire à des flots de paroles qui prennent l'enfant à témoin de la peine des adultes sans lui laisser sa place d'enfant.

Je me permettrais un conseil paradoxal: une deuxième lecture m'apparaît indispensable et elle devrait être débutée par la fin, par la conclusion! Parce qu'on y explique ce que parler avec l'enfant veut dire! "On ne lui parle pas comme à un adulte [...] pour savoir ce qu'il peut entendre, il faut d'abord l'écouter" (p. 134) et "notre souffrance ne s'exprime pas comme la sienne, alors ne projetons pas la nôtre sur lui, il ne s'y reconnaîtrait pas». Et si on relisait ce livre avec cette conclusion en tête, on découvrirait des nuances, des petites phrases de-ci de-là, des pistes de réflexion pour le parent lui-même en deuil afin de l'aider à départager entre son deuil et celui que vit l'enfant.

Donc, un livre qui s'adresse aux parents, je dirais aux parents à l'aise avec les notions et le vocabulaire psychologique, psycho-dynamique; un livre à relire pour saisir toutes les pistes de réflexion proposées; une auteure qui prête une attention particulière aux jeunes et très jeunes enfants; un livre qui intéressera aussi les intervenants par ses nuances et sa sensibilité.

Louise Rousseau 